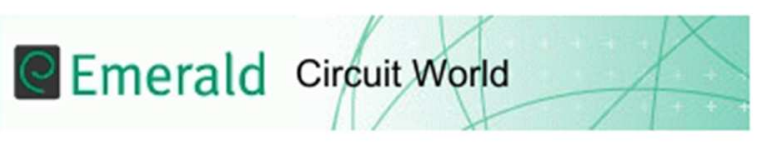

Morphology and acoustic artefacts of copper deposits electroplated using megasonic assisted agitation

\begin{tabular}{|r|l|}
\hline Journal: & Circuit World \\
\hline Manuscript ID & CW-03-2016-0006.R1 \\
\hline Manuscript Type: & Research Paper \\
\hline Keywords: & $\begin{array}{l}\text { printed circuit board, Megasonic agitation, copper, Electroplating, Acoustic } \\
\text { streaming }\end{array}$ \\
\hline \multicolumn{2}{|c}{} \\
\hline
\end{tabular}


1

2

3

4

5

6

7

8

9

10

11

12

13

14

15

16

17

18

19

20

21

22

23

24

25

26

27

28

29

30

31

32

33

34

35

36

37

38

39

40

41

42

43

44

45

46

47

48

49

50

51

52

53

54

55

56

57

58

59

60

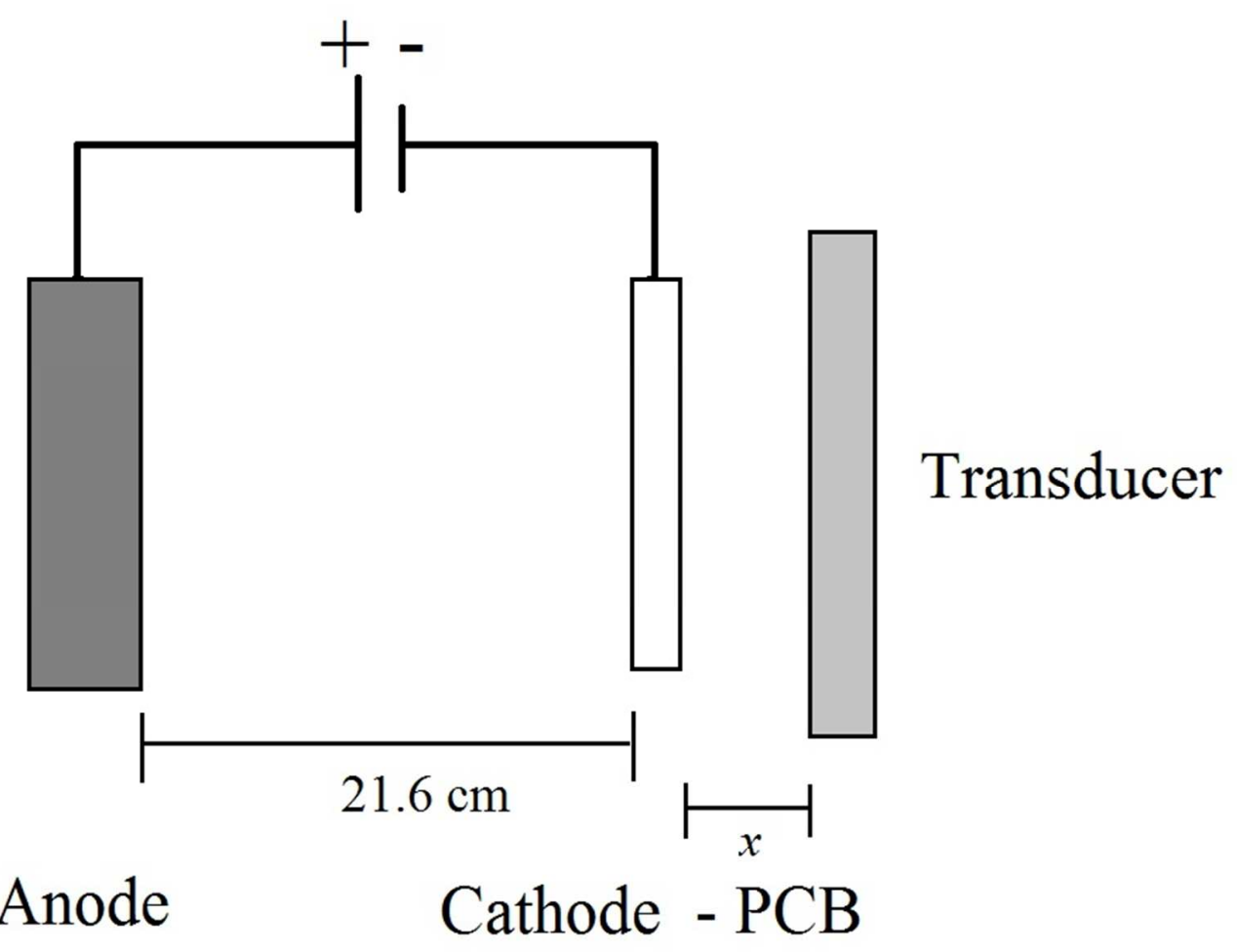

Figure 1 - A schematic of the plating cell setup indicating tangential distance $\mathrm{x}$ from PCB to transducer. 


\begin{tabular}{|c|c|c|c|c|c|}
\hline \multirow{2}{*}{$\begin{array}{l}\text { Experiment } \\
\text { Number }\end{array}$} & \multirow{2}{*}{$\begin{array}{c}\text { Plating } \\
\text { Parameter } \\
\text { Alte red }\end{array}$} & \multicolumn{2}{|c|}{ Experiment Plating Parameters } & \multirow[b]{2}{*}{ Me as ure ment obtained } & \multirow[b]{2}{*}{ Purpose } \\
\hline & & Transducer & $\begin{array}{l}\text { Electrical } \\
\text { Current } \\
\text { Density } \\
\left(\mathrm{A} / \mathrm{dm}^{2}\right)\end{array}$ & & \\
\hline 1 & \multirow{3}{*}{$\begin{array}{l}\text { Acoustic } \\
\text { Power }\end{array}$} & $\begin{array}{c}\text { Position : Tangential, } \\
X=1 \mathrm{~cm} \\
\text { Power : } 0 \mathrm{~W}, 225 \mathrm{~W}, \\
450 \mathrm{~W} \\
\end{array}$ & 4 & $\begin{array}{l}\text { Qualitative observations of Cu grain } \\
\text { structure using an Optical and Scanning } \\
\text { Electron Microscopes (SEM). }\end{array}$ & $\begin{array}{l}\text { Reveals acoustic influence on surface } \\
\text { chemical additives. }\end{array}$ \\
\hline 2 & & $\begin{array}{c}\begin{array}{c}\text { Position : Tangential, } \\
X=1 \mathrm{~cm}\end{array} \\
\text { Power : } 0-450 \mathrm{~W}\end{array}$ & 2 & $\begin{array}{l}\text { Quantitative measurements of } \mathrm{Ra} \text { in re- } \\
\text { sponse to changes in acoustic transducer } \\
\text { power output, obtained using white light } \\
\text { interferometer. }\end{array}$ & $\begin{array}{l}\text { Notes how Ra changes with acoustic } \\
\text { power autput highlighting power- } \\
\text { dependent influence on plated finish quali- } \\
\text { ty. }\end{array}$ \\
\hline 3 & & $\begin{array}{c}\text { Position : Tangential, } \\
X=1 \mathrm{~cm}, 10 \mathrm{~cm} \\
\text { Power : } 225 \mathrm{~W}\end{array}$ & 2 & $\begin{array}{l}\text { Quantitative measurements of Ra in re- } \\
\text { sponse to changes to acoustic transducer } \\
\text { tangential distance, obtained using a white } \\
\text { light interferometer. }\end{array}$ & $\begin{array}{l}\text { Notes how Ra changes with distance } \\
\text { highlighting position-dependent influence } \\
\text { on plated finish quality. }\end{array}$ \\
\hline 4 & \multirow{2}{*}{$\begin{array}{c}\text { Electrical } \\
\text { Current }\end{array}$} & $\begin{array}{c}\begin{array}{c}\text { Position : Tangential, } \\
X=1 \mathrm{~cm}\end{array} \\
\text { Power : } 225 \mathrm{~W}\end{array}$ & 1 & $\begin{array}{l}\text { Qualitative observations of } \mathrm{Cu} \text { grain } \\
\text { structure using SEM in response to current } \\
\text { density variation across } \mathrm{PCB} \text { surface. }\end{array}$ & $\begin{array}{l}\text { Highlights distance dependent current } \\
\text { thieving effect by transducer device and } \\
\text { characterises adverse plating produced in } \\
\text { response. }\end{array}$ \\
\hline 5 & & $\begin{array}{c}\text { Position : Tangential, } \\
X=1 \mathrm{~cm} \\
\text { Power : } 0 \mathrm{~W}, 225 \mathrm{~W}\end{array}$ & 2,4 & $\begin{array}{l}\text { Qualitative observation of } \mathrm{Cu} \text { grain struc- } \\
\text { ture using SEM in response to varying } \\
\text { plating current densities. }\end{array}$ & $\begin{array}{l}\text { Highlights changes to } \mathrm{Cu} \text { crystallinity } \\
\text { displaying acoustic influence on bath addi- } \\
\text { tives and potential performance issues. }\end{array}$ \\
\hline
\end{tabular}

A list of the individual experiments with their parameters, measurement obtained and purpose. 


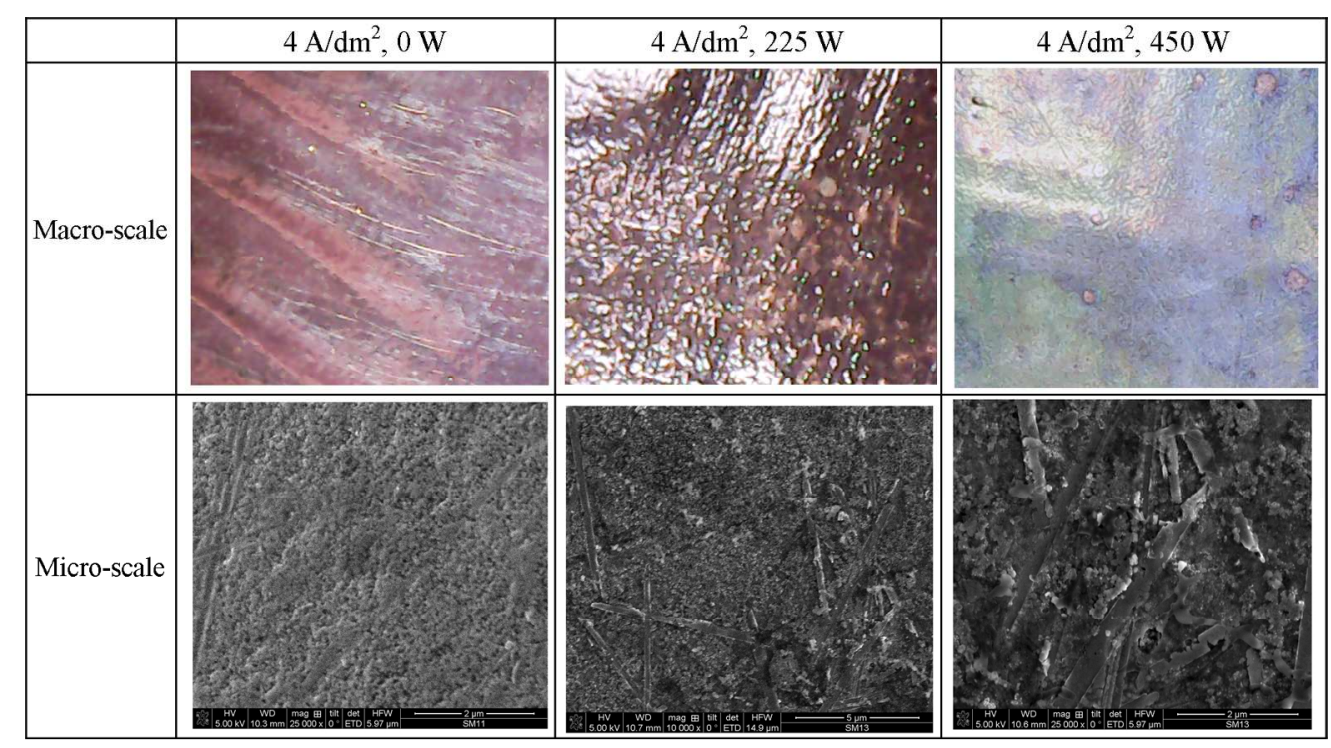

Macro-scale and micro-scale SEM images for surfaces plated under silent (0 W) and MS-agitation (225 and $450 \mathrm{~W})$. 


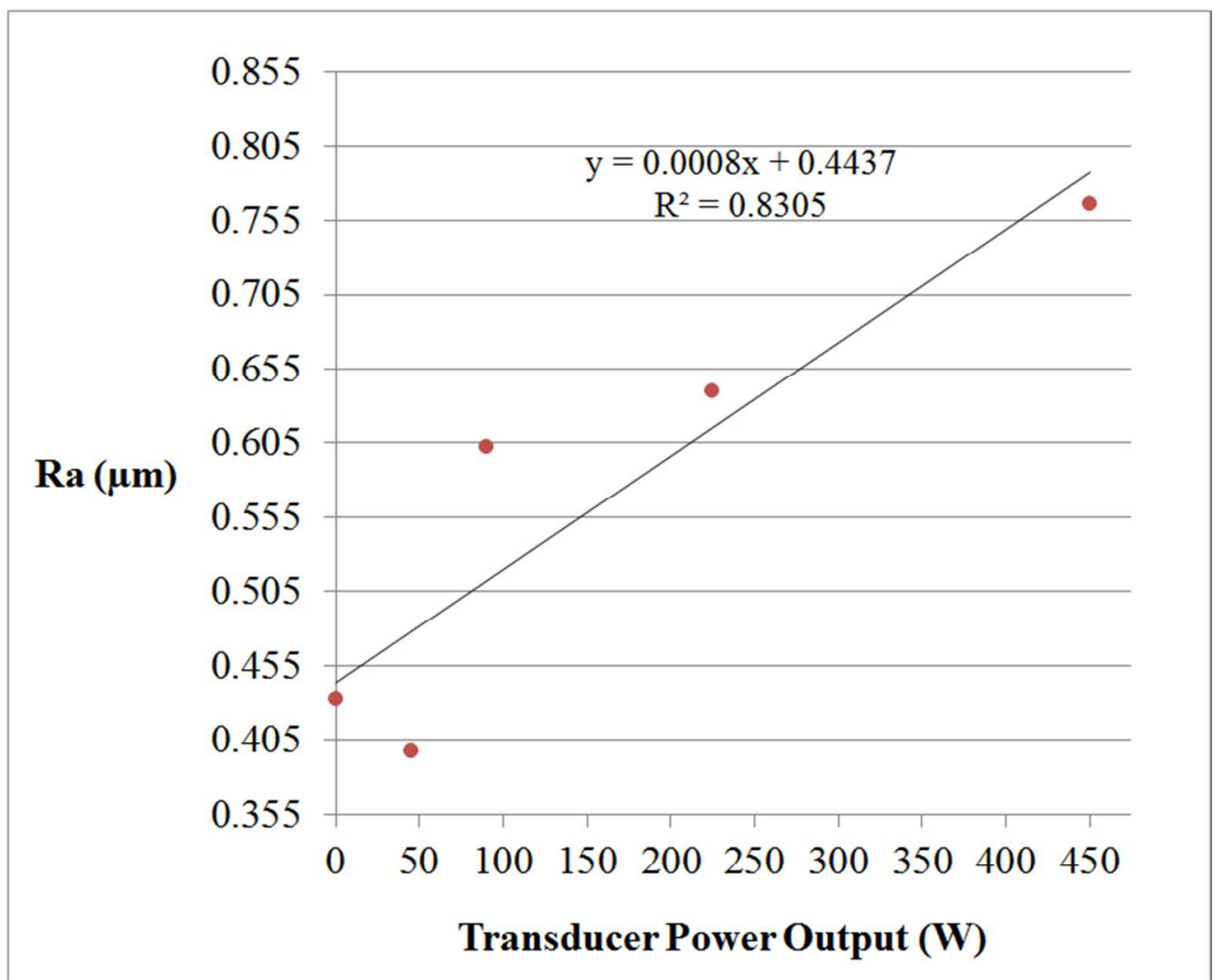

A plot of Ra measured using a white light interferometer for an area $6.1 \mathrm{~mm}^{2}$, highlighting the variation in response to transducer acoustic power output. 
A.
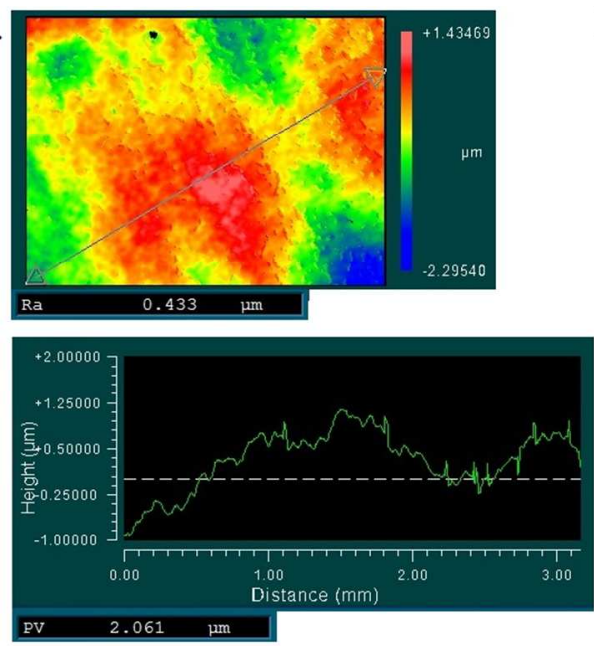

B.
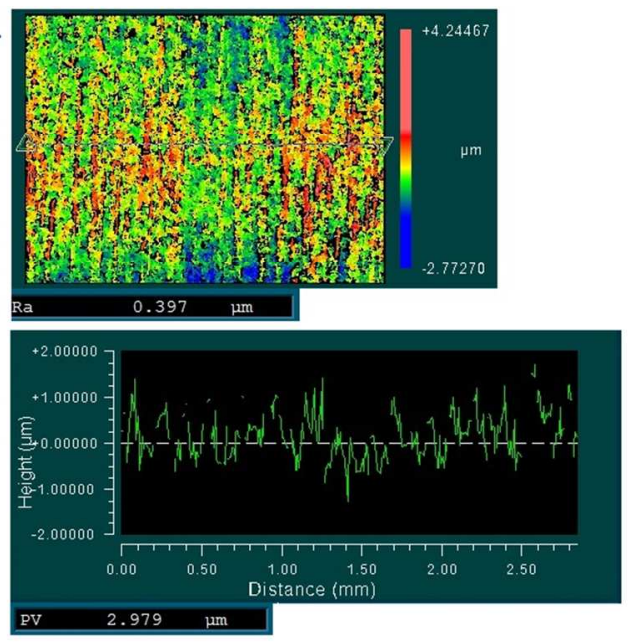

Figure 3 - Top-down images of PCB surfaces of areas $6.1 \mathrm{~mm}^{2}$ using a white light interferometry with cross section profiles included underneath. Labels $A$ and $B$ indicate 0 and $45 \mathrm{~W}$ output power, respectively. 
A.
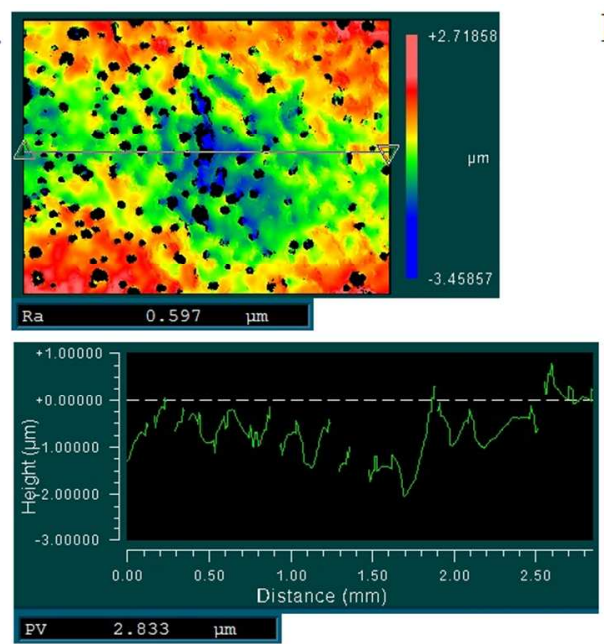

B.
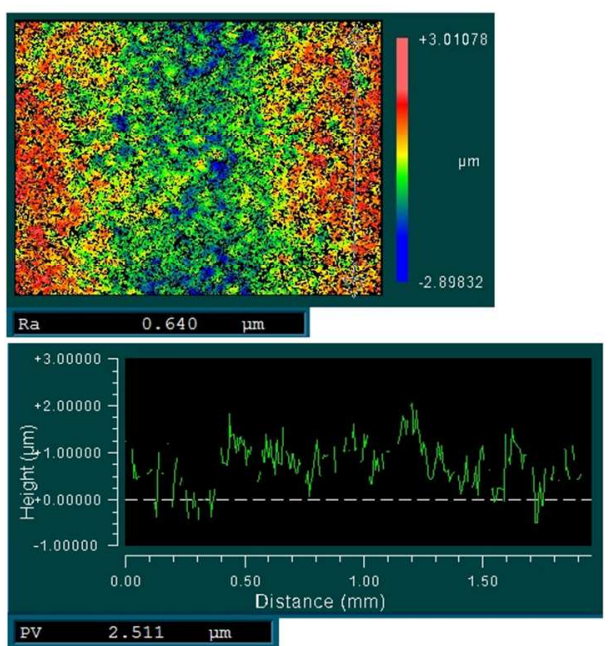

Figure 4 - White light interferometer plots of Cu plated PCB surfaces of areas $6.1 \mathrm{~mm}^{2}$, with cross-section profiles included underneath. A: transducer positioned $10 \mathrm{~cm}$ from the PCB. B: transducer is positioned at 1 $\mathrm{cm}$. 


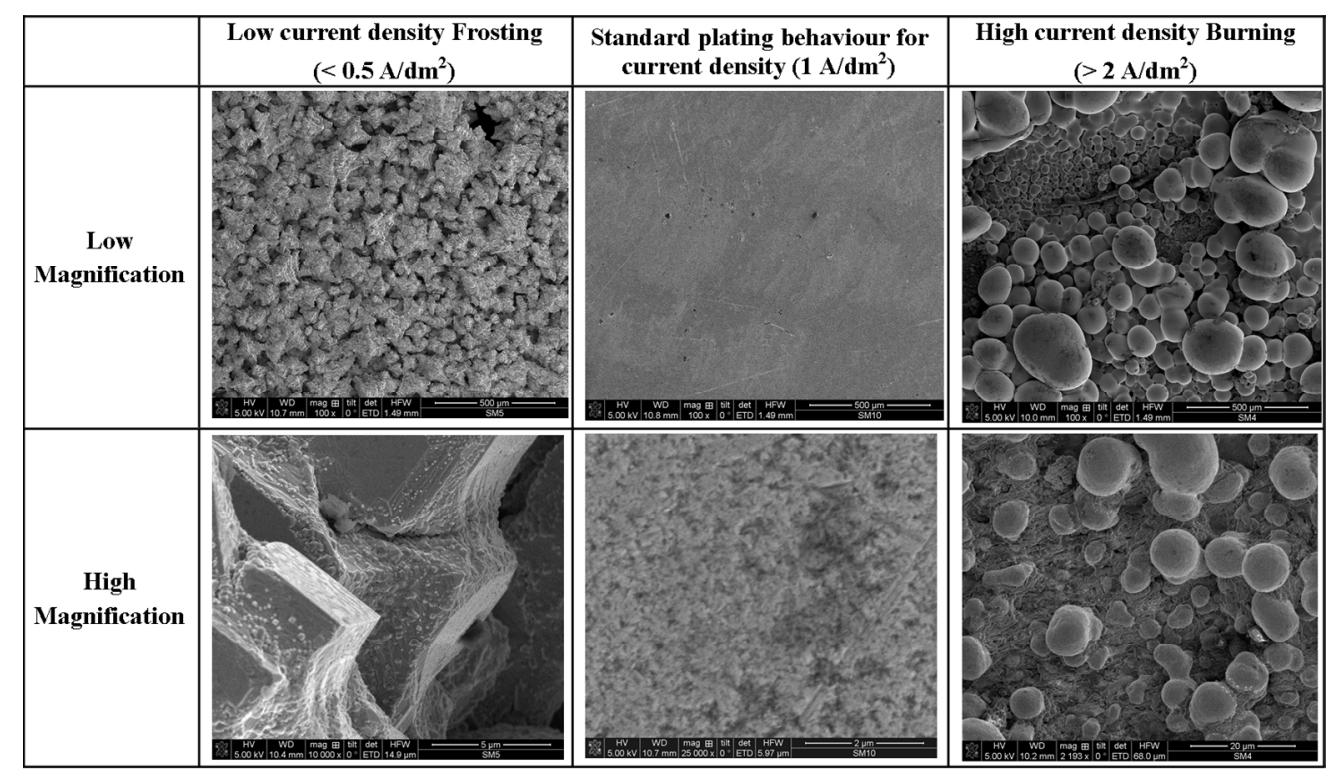

Table 3 - Plating behaviours observed during megasonic energy assisted electroplating. 


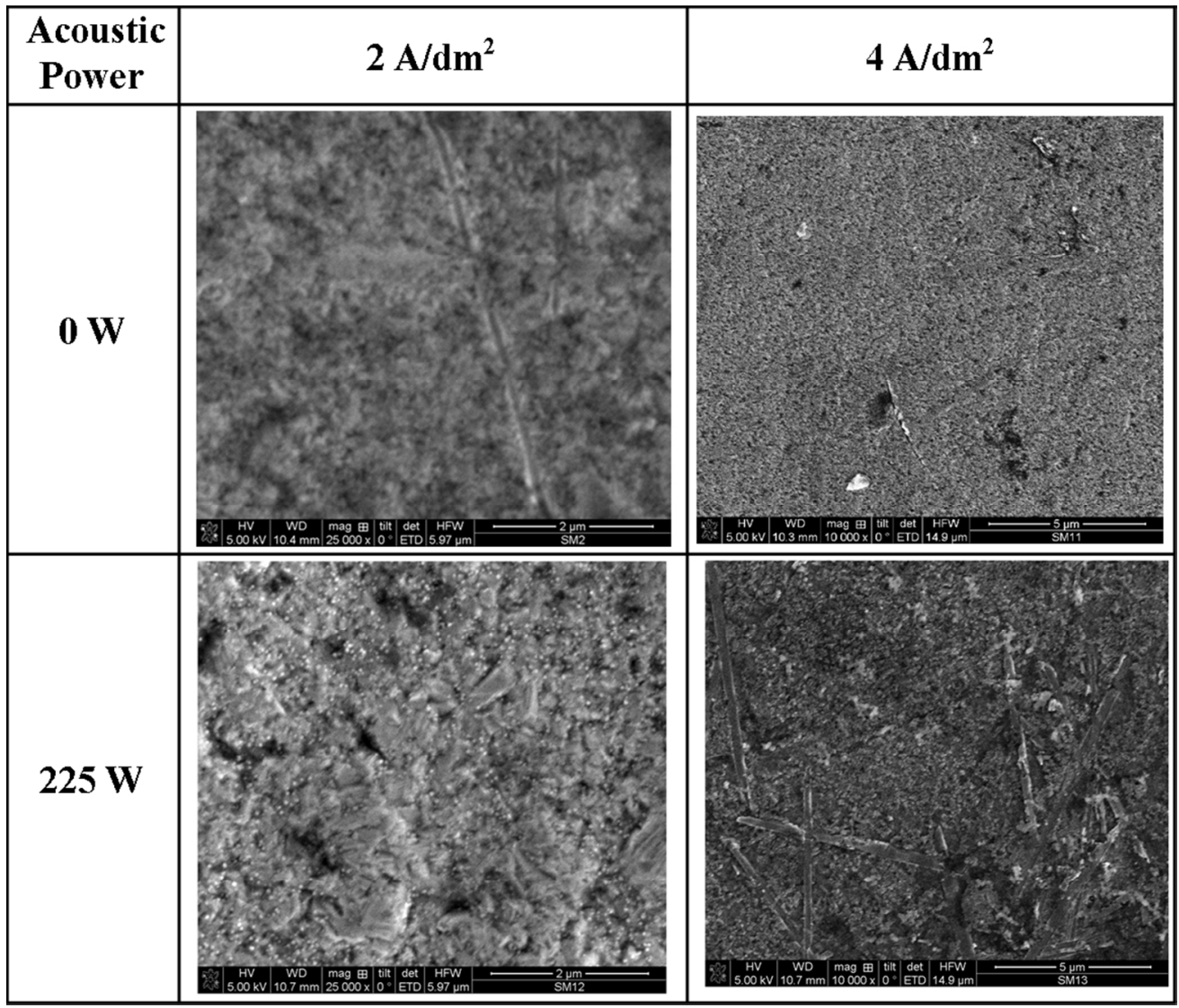

Table 4 - SEM images of PCB surfaces plated under varying current densities and MS-agitation. 

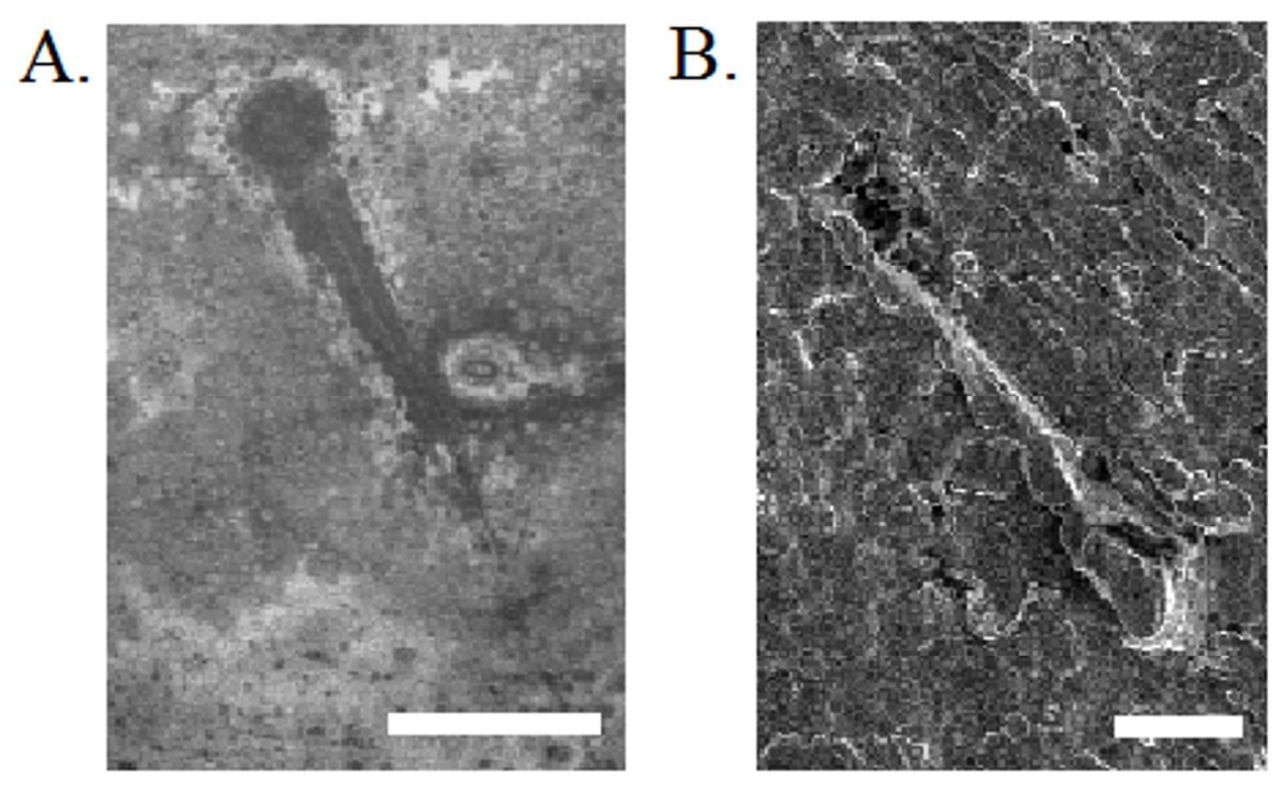

Figure 5 - Observations of megasonic assisted cavitation. A) Obtained using an interferometer, scale in image $1 \mathrm{~mm} \mathrm{~B}$ ) SEM image, scale in image $5 \mu \mathrm{m}$. 

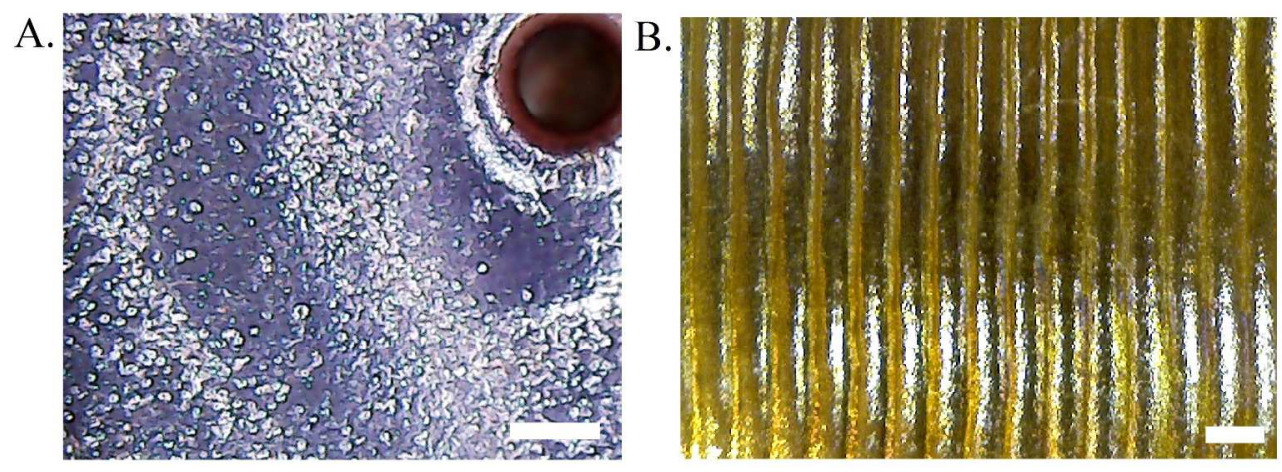

Figure 6 - Images of surface acoustic waves in electrodeposited copper. A) Formation of ringlets with scale bar $0.5 \mathrm{~mm}$. B) Ridges with scale bar $1 \mathrm{~mm}$. 


\title{
Morphology and acoustic artefacts of copper deposits electroplated using megasonic assisted agitation
}

\begin{abstract}
Purpose - A study of the influence of megasonic (MS) assisted agitation on Printed Circuit Boards (PCBs) electroplated using copper electrolyte solutions, to improve plating efficiencies through enhanced ion transportation.
\end{abstract}

Design/methodology/approach - The impact of MS assisted agitation on topographical properties of the electroplated surfaces studied, through a Design of Experiments (DOE), by measuring surface roughness, characterised by values of the parameter $\mathrm{Ra}$ as measured by white light phase shifting interferometry and high resolution scanning electron microscopy.

Findings - An increase of Ra from $400 \mathrm{~nm}$ to $760 \mathrm{~nm}$ measured after plating, for an increase to acoustic power from $45 \mathrm{~W}$ to $450 \mathrm{~W}$. Roughening increase due to micro-bubble cavitation energy, supported through direct imaging of the cavitation. Current thieving effect by the MS transducer induced low-currents, leading to large $\mathrm{Cu}$ grain frosting reducing the board quality. Current thieving was negated in plating trials through specific placement of transducer. Wavy electroplated surfaces, due to surface acoustic waves, also observed reducing the uniformity of the deposit.

Research limitations/implications - The formation of unstable transient cavitation and variation of the topology of the copper surface are unwanted phenomena. Further plating studies using megasonic agitation are needed, along with fundamental simulations, to determine how the effects can be reduced or prevented.

Practical implications - Identify manufacturing settings required for high-quality MS assisted plating and promote areas for further investigation, leading to the development of an MS plating manufacturing technique.

Originality/value - Quantification of the topographical changes to a PCB surface in response to megasonic agitation and evidence for deposited copper artefacts due to acoustic effects.

Keywords Printed Circuit Boards, Megasonic agitation, Copper, Electroplating, Acoustic streaming

Paper type Technical paper

\section{Introduction}

Copper $(\mathrm{Cu})$ electroplating is a technique employed for the metallisation of Printed Circuit Boards (PCBs) surfaces to allow individual layers to be electrically interconnected.New methods of fine reselution electrodeposition are being sought which still offer economical manufacturing solutions, to support the 
increasing performance requirements within the PCB industry, such as larger aspect ratio, driven by a demand for a higher number of electronic components and stacking densities of PCB layer. The technological growth of high-value PCBs is currently driven by the development of boards which can propagate high frequency signals above $1 \mathrm{GHz}$ (Okubo et al., 2013) with transmission speeds over $25 \mathrm{~Gb} / \mathrm{s}$ (Muller et al., 2015) and at low bit error rates. Additionally, small track feature sizes are desired to allow for large board component densities. Successfully applying these properties introduces a strain on the manufacturability of the board, specifically related to a) the ability to fabricate small interconnects and b), the maintenance_of a low signal error and on-board device component performance, despite increasing thermal transport issues due to higher power and denser board designs (Gurrum et al., 2012). These issues may be addressed in PCB construction through the fabrication of small diameter - less than $0.2 \mathrm{~mm}-$ Vertical Interconnect Access (VIA) interconnects of high thickness-to-width aspect ratio, which are uniformly filled with $100 \% \mathrm{Cu}$. Such interconnects would enable a) increased electrical and thermal conductivity, over the partially plated vias and b) multilayer fabrication with less thermally intensive bonding operations, increasing board lifetime and reducing fabrication costs. Such boards would be especially desirable in the mobile phone market which employs $\mathrm{Cu}$ filled THVs, of low aspect ratio of $4: 1$, as these currently require high fabrication costs due to special filling chemistry and plating waveforms (Roelfs et al., 2013).

A candidate method to enhancing the performance of traditional electroplating and providing $\mathrm{Cu}$ filling, is the introduction of a megasonic $(1 \mathrm{MHz})$ transducer as a way to induce acoustic streaming to enhance $\mathrm{Cu}$ ion transfer. The introduction of megasound has been shown to improve plating speed and filling quality, on the electrodeposition of $\mathrm{Cu}$ in situations where the ratio between thickness down the via and on the surface is close to 1:1 (Hyde and Compton, 2002, Costello et al., 2013).

Megasound (MS), defined here as sound waves of frequencies higher than $700 \mathrm{kHz}$, and ultrasoundbased (US) $(0.02 \mathrm{MHz}-0.7 \mathrm{MHz})$ agitation processes generate different forces on the surface of a substrate, which are induced either by acoustic cavitation or acoustic streaming flow. Cavitation is defined as the formation of a bubble under sonication, produced as a result of localised fluid medium size variations, which are brought on due to high tensile stresses occurring during the low pressure phase of an acoustic wave. Depending on the life cycle and dynamics of the bubble, cavitation can be either stable or transient. Stable cavitation describes the formation of bubbles, which, during their lifetime cycle, do not change significantly in their equilibrium position or size. In contrast, transient cavitation, is the energy release through an exothermic implosion, occurring from the collapse of air bubbles when local pressures in a fluid decrease to below a minimum vapour pressure, defined as the absolute pressure, for a given temperature, at which the liquid vaporises or is converted to a gas (Martin, 2013). The occurrence of cavitation depends on the pressure, amplitude and frequency of an acoustic wave. At ultrasonic frequencies the transient cavitation may cause considerable damage to a metal surface. The energy released depends on the size of the bubble which is influenced by the frequency of the acoustic agitation. For MS frequencies the cavitation bubble size is smaller than for US, as demonstrated in sono-luminescence studies which show that, at $1.056 \mathrm{MHz}$, 
cavitation is produced from bubbles of diameters approximately $2 \mu \mathrm{m}$ and $3 \mu \mathrm{m}$ for ultrasound frequency of $0.647 \mathrm{MHz}$ (Brotchie et al., 2009). Accordingly, agitation by US energy will create a rougher surface topography, due to the more aggressive nature of the process, as demonstrated on a $\mathrm{Cu}$ surface (Verdan et al., 2003). Similarly US energy is used in cleaning medical devices (Verhaagen and Fernández, 2016).

A sound wave traveling within a fluid medium induces a forcing effect per unit volume, governed by the spatial variation of the Reynolds stress component of the acoustic wave. Such an effect generates a steady streaming motion within the fluid along the propagation of the acoustic wave (Hoffelner et al., 2000). At the interface of the bath solution/PCB a diffusion layer exists into which $\mathrm{Cu}$ cations are transported. Increases in acoustic power and frequency enable thickness reduction of this layer due to acoustic streaming convection (Abdollah et al., 2003). This reduction, in turn, increases the limited current density, which enables a larger, more efficient plating reaction. For MS frequencies the layer is reduced further compared to US, enabling access to higher limited current densities (Kaufmann et al., 2011).

Compared to US, MS offers less aggressive agitation due to the reduction in cavitation forces and higher plating efficiency due to the reduction of the diffusion layer (Strusevich et al., 2013). Studies have provided in-depth analysis of electrochemical behaviour during the plating trials; however, they have offered a limited analysis of the changes in topography of the electrodeposits. A desired surface topography postelectrodeposition, is a trade-off between the manufacturability of the PCB and its use for a given application. A metal surface roughness of size $0.3 \mathrm{~mm}$ (Trelleborg, 2008) is efficient for manufacturing, as it enables adhesion of dry-film resist and surface finish plating such as electrolytic silver. For high frequency $(\geq 1$ $\mathrm{GHz}$ ) applications, a large surface roughness in the PCB manufacture would be undesirable, as electrical signals transmitted through surface $\mathrm{Cu}$ features undergo increased bit error rates for surface roughness increases (Okubo et al., 2013).

Understanding and controlling how deposited $\mathrm{Cu}$ roughness varies during processing is therefore critical in introducing a successful surface modifying procedure into PCB manufacture. Research on US agitation has included rigorous investigations to define its impact when used for metal surfaces (Verdan et al., 2003, Cravotto et al., 2013). In contrast, little research has been carried out on the impact of MS-assisted plating on $\mathrm{Cu}$ topography, excepting work highlighting that a polycrystalline finish was favoured (Kaufmann et al., 2009). In response to this, the following article provides a Design of Experiments which studies the impact of MS agitation on the PCB surface during standard $\mathrm{Cu}$ electroplating.

Changes to topography were quantified using the parameter $R a$ defined as the arithmetic average, over a sampling length of area, of peak heights and troughs from the mean height of electrodeposits (Peiponen et al., 2009). A visual characterisation of a surface after a plating cycle can be used to infer the electroplating conditions under which the deposit was plated, as changes to plating settings alter $\mathrm{Cu}$ grain size and thus the surface topography. The quality of a plated finish is characterised on the microscale by a fine grain structure and on the macroscale by a shiny finish. A variety of plating finishes were obtained in the 
MS trials performed. Through these trials, this article outlines some of the key effects observed on the plated $\mathrm{Cu}$ topography and highlights some of the unique plated artefacts produced in response to the MS agitation.

\section{Experimental Investigation}

The plating trials were performed on FR4 PCBs at Merlin Circuit Technology Ltd. based in Deeside, North Wales. The trials were performed in an experimental $500 \mathrm{~L}$ plating tank using soluble anodes. The plating schematic is indicated in Fig 1. The tangential distance of the anode basket to the cathode PCB is $21.6 \mathrm{~cm}$. This setting has been optimised previously by Merlin Circuit for the plating bath geometry, as it maximises the plating uniformity across the PCB (Garich et al., 2007) and was applied in PCB manufacture prior to these investigations. The plating bath chemistry, intended for direct current (DC), pulse plating and periodic reverse-pulse plating (AC), was made-up using SLOTOCOUP CU110 supplied by Schloetter Ltd. When operating under the recommended electrolyte solution manufacturer's conditions, a high quality finish is produced, which is characterised as fine grained and ductile. The chemistry was comprised of $80 \mathrm{~g} / \mathrm{L}$ copper sulphate, $100 \mathrm{ml} / \mathrm{L}$ sulphuric acid and $80 \mathrm{mg} / \mathrm{L}$ chloride. Chemical proprietary additives $\mathrm{Cu} 111$ (5 $\mathrm{mL} / \mathrm{L})$ and $\mathrm{Cu} 114(5 \mathrm{~mL} / \mathrm{L})$ were included in the solution.

The transducer system, manufactured by the Company Sonosys, is a square-faced submersible composed of four rectangular piezo-transducers, of size $2.5 \mathrm{~cm}$ by $11 \mathrm{~cm}$, embedded in a steel sheet of 1.03 $\mathrm{dm}^{2}$ area. The PZT outputs a $1 \mathrm{MHz} \pm 0.05 \mathrm{MHz}$, acoustic wave with a variable power, where, at $100 \%, 500$ $\mathrm{W}$ of electrical power is supplied to the piezoelectric emitter, which is converted to acoustic power output with a conversion efficiency of around $90 \%$. The device was positioned tangentially to the PCB surface at a distance $X$ within the plating bath using a scaffolding arrangement. The setup schematic is highlighted in Fig 1 , with tangential distance altered according to the experimental setup. In all setups the acoustic wave within the bath was unidirectional due to the small beam spread angle attributed to high frequency acoustics (Brennan, 2007) and covered an area approximate to the area of the transducer face.

Figure $1 \mathrm{~A}$ schematic of the plating cell setup indicating tangential distance $x$ from PCB to transducer.

\subsection{Observation metrics and methods}

After plating a sample was taken from the PCB of area $1 \mathrm{~cm}^{2}$ using a Dremel 200 Multi-tool (RS), (UK). The sample was obtained from a region of interest for that investigation so as to highlight plating dynamics. The topography of the plating results was analysed using a Zygo Viewmeter white light phase shifting interferometer, at Heriot-Watt University, which measured the $R a$ over sample sizes scales $6.1 \mathrm{~mm}^{2}$ and $24.4 \mathrm{~mm}^{2}$ and provided 2D images of the PCB surface (zygo, 2016). The electrodeposited material was additionally evaluated from high-resolution images of the PCB surface, imaging between area scales $35 \mu^{2}$ and $1.88 \mathrm{~mm}^{2}$ using a Scanning Electron Microscope (SEM) also at Heriot-Watt University. 


\subsection{Design of Experiments}

Experiments were grouped into those looking at changes induced by variations of the transducer acoustic power, and those occurring due to changes to the electrical current density. A series of five experiments were performed as displayed in Table 1, which highlights the individual settings applied, the measurement technique used to analyse and the purpose of the measurement.

A change in transducer output power alters the magnitude of the acoustic force on the surface of a PCB which in turn affects the $\mathrm{Cu}$ deposition. Categorising the impact of acoustic power on deposit properties provides a useful metric to control MS plating output. Experiments $1-3$ altered the setup of the transducer, which, in turn, changed the acoustic power reaching the board surface. Experiment 1 used SEM and optical measurements of the surface to demonstrate how acoustic pressure influences the crystalline grain structure of the deposit; an important metric for defining quality. Experiment 2 investigated altered surface topography due to changes to the power output from the transducer from 45 to $450 \mathrm{~W}$, for a fixed distance. Using the interferometer, measurements of $R a$ were taken and the values plotted on a graph for analysis. Plots of the changes in height over areas of $6.1 \mathrm{~mm}^{2}$ were obtained and a qualitative analysis was made placing the observed features in the context of known plating behaviours and material compositions. Experiment 3 made changes to the transducer position to highlight variation in the electrodeposition. For example, increasing the distance of the transducer to the PCB alters the power of the acoustic wave when it reaches the surface due to attenuation (Etter, 1995). Measurements of $R a$ highlighted changes to surface topography in response to the transducer distance.

Changes of the $\mathrm{Cu}$ crystalline deposits were also investigated as a function of the electrical current. When fabricating a PCB the electrical current density is a key parameter for the control of the thickness and granularity of the electrodeposited metal. The layout of the electrical tracks on the surface of a board influences also the plating behaviour. For the plating dynamics to match quality and design specifications for the PCB customer, an operator needs to alter the electrical current settings to plate a desired thickness and morphology. To develop MS plating as a technique it is therefore important to characterise the behaviour of an electrodeposit in response to current variation, so as to highlight any adverse effects. Experiment 4 investigated the change to plated crystallinity across the PCB surface when the transducer was setup at a close distance, $1 \mathrm{~cm}$, to the PCB surface. The transducer was setup with a close proximity to maximise the acoustic agitation reaching the PCB surface, at the expense of attracting current away from the PCB surface. Experiment 5 investigated changes to plating crystallinity in response to alterations to electrical current density. For both experiments observations were made from high resolution SEM images and height measurements, which enabled comparison to known topographies and structures for the conditions under which they were deposited.

Throughout the experiments adverse $\mathrm{Cu}$ artefacts were observed in the form of ripples and craterlike features on the surface of the PCBs after plating with MS agitation. These artefacts were analysed using qualitative observations of SEM and optical images, so as to identify the mechanism behind their formation and the processing parameters required to prevent them. 
Table $1 \mathrm{~A}$ list of the individual experiments with their parameters, measurement obtained and purpose.

\section{Results and Analysis}

\subsection{Influence of Acoustic Power on Electrodeposit Properties}

\subsubsection{Experiment 1: Acoustic power impact on Cu grain structure}

A PCB $\mathrm{Cu}$ finish provides an indicator of plating quality, where a ductile and uniform coverage of copper indicates a good plating process. If air pockets exist in a deposit then expansion of gas in the cavity may cause the board to fracture and, in the worst case scenario, result in an opening of the electrical circuit. $\mathrm{Cu}$ deposits can be categorised as either fine-grain, columnar or dendritic. A fine grain deposit is desired and is characterised by high density, high uniformity and random crystal orientations. This deposit indicates the correct operation of the plating bath parameters and is typically observed as a shiny plating finish. A columnar structure includes deposits containing larger grains with an orientation perpendicular to the PCB surface following grain boundaries. This deposit is not desirable as it induces a large variation in uniformity on the PCB surface. A dendritic deposit, not observed during our trials, is a fibrous deposit of morphology intermediate between the first two structures. Grain structure is influenced by all of the plating parameters, where a change made to one parameter can induce an undesired grain structure change. For this reason, the bath chemistry is carefully formulated by the chemical suppliers and maintained by the PCB fabricator, so as to ensure a high quality electrodeposit (Yan et al., 2013).

The first experiment was plated under conditions highlighted in Table 2. The surface displayed a shiny electrodeposit. From this observation, it would be predicted that the surface had a fine grain deposit like the micro-scale image of the PCB plated under silent conditions as shown in Table 2. With MS at $225 \mathrm{~W}$ and $450 \mathrm{~W}$, the micro-scale SEM images revealed however spiky, whisker-like randomly oriented grains. $\mathrm{Cu}$ whiskers are characteristic of an electrodeposit formed by poor chemical additive performance and high current density, and are different from dendritic deposits, which have a fractal-like appearance. The whiskers were layered due to diffusion-limited aggregation of the $\mathrm{Cu}$. The filament/granular nature of the $\mathrm{Cu}$ whisker growth was possibly due to the uninterrupted crystal facets as they were quickly deposited on the PCB due to the high current density. The random nature of the whisker orientation was likely due to the protruding tips, which locally increased the electrical current density and enhanced their growth relative to the surrounding uniform $\mathrm{Cu}$ structures (Minzari et al., 2011). The spiky deposits were not prevalent over the entire surface of the PCB, enabling the appearance of a shiny deposit on the macroscale. Regardless, the spiky deposits present are likely to cause issues for PCB quality, particularly with reference to its structural stability, as large crystals are more susceptible to fracturing and breaking (Schlesinger and Paunovic, 2011). For this reason the mechanical properties of the deposit may not be sufficient to match the Association Connecting Electronics Industries (IPC) standards (Lee et al., 2010). 
Table 2 Macro-scale and micro-scale SEM images for surfaces plated under silent $(0 \mathrm{~W})$ and MS| agitation (225 and $450 \mathrm{~W})$.

\subsubsection{Experiment 2: Interferometric measurements of Ra of PCB surface as a function of transducer power variation}

The second experiment was performed to investigate the influence of the transducer power output on the plated surface finish. Measurements of $R a$ was obtained using a white light phase shifting interferometer and plotted against power increase, as displayed in Fig 2. For each measurement, the transducer was set up and the plating settings chosen as indicated in Table $1 . R a$ increased by $205 \%$ as the output power increased from 45 to $450 \mathrm{~W}$. Between $0 \mathrm{~W}$ and $45 \mathrm{~W}$ there was a $9 \%$ decrease in $R a$.

It is possible that the natural variation of roughness due to the glass weave influenced the result, adding a random variation to the data. A PCB is comprised of a glass weave encapsulated in an epoxy resin. The weave causes a natural large scale height variation, defined as waviness, of around $6 \mu \mathrm{m}$ across the PCB surface (IPC, 1999). When evaluating $R a$ the sample length is chosen so that the long wavelength features do not interfere with the calculation. The sampling length area chosen should be large enough to encompass the small-wavelength (roughness) features, yet small enough so that it does not include the large-wavelength (wavy) features. If the sampling length is increased to include the wavy features then the $R a$ parameter will be influenced by this and increase. To highlight this further, data from the interferometer was used to plot top-down images of the electroplated surface for $0 \mathrm{~W}$ and $45 \mathrm{~W}$ as indicated in Fig 3. Under silent conditions the wavy features were observed on the PCB contributing to an approximate $2 \mu \mathrm{m}$ Peak-to-Valley height. When $45 \mathrm{~W}$ MS agitation was applied, the surface displayed considerable micro-roughening, which was not detected by the interferometer in the evaluation for $R a$, highlighting measurement device limitation. The reduction in $R a$ measured from $0 \mathrm{~W}$ to $45 \mathrm{~W}$ could be accounted for by the wavy features on the PCB and as such, the roughness increase at $45 \mathrm{~W}$ highlighted in the cross-section profiles in Fig 3, was not measurable using the interferometer. To detect the influence of the transducer at low acoustic outputs, for this reading a smaller sampling area would have had a greater chance of measuring the roughness variation, although this would have been closer towards the detection limit of the device-should have been used.

For transducer powers larger than $45 \mathrm{~W}$ an increase in roughness was measured for an increase in pressure output. At $90 \mathrm{~W}$ the roughness was significantly large so that the wavy features on the board did not interfere with the measurement. A linear dependence of Ra was indicated on the plot. Tthe increasesd in roughness measured with increasing transducer powers -areas most likely due to cavitation effects, where higher acoustic pressures enhanced the frequency of the cavitation effects_(Ebnesajjad, 2010). as observed when the transducer was setup at smaller distance seales-The cavitation damage influencing Ra is more difficult to quantify as a function of acoustic pressure as it depends on localised variations in fluid medium density, bubble diameter size, and bath chemical composition and temperature (Brotchie et al., 2009). An 
analysis into these individual effects and their impact on $\mathrm{Ra}$ is required, to derive a relationship and make predictions on the behaviour of the acoustics on Ra. This analysis is beyond the scope of this article.

It is uncertain over which area-scale the impact on roughness, due to cavitation forces, was most evident, although they are observable over the $6.1 \mathrm{~mm}^{2}$ scale. At this scale, the results show that the natural undulations of the PCB laminate impact on the measurement for surface roughness, making it difficult to extract their influence at low power outputs but was possible at $90 \mathrm{~W}$ and higher.

Figure 2 A plot of Ra measured using a white light interferometer for an area $6.1 \mathrm{~mm}^{2}$, highlighting the variation in response to transducer acoustic power output.

Figure 3 Top-down images of PCB surfaces of areas $6.1 \mathrm{~mm}^{2}$ using a white light interferometry with cross section profiles included underneath. Labels $A$ and $B$ indicate 0 and $45 \mathrm{~W}$ output power, respectively.

\subsubsection{Experiment 3: Interferometric measurements of Ra as a function of distance between transducer and $P C B$}

The aim of the third experiment was to highlight how an increase of the distance between the transducer and the PCB alters the surface roughness of the electrodeposit formed, as the acoustic streaming force is reduced on the surface. Highlighted in Fig 4 are two top-down images of the $6.1 \mathrm{~mm}^{2}$ PCB surface area. Variations in height are indicated by changes of colour and by the cross section profiles. The labels A and B highlight two different PCBs plated with the transducer setup at distances of $10 \mathrm{~cm}$ and $1 \mathrm{~cm}$, respectively, under conditions outlined in Table 1. Dark regions in the figure can either be due to steep and vertical protrusions, depressions, or saturation of the detector due to high reflectivity of the surface. In A, these dark pixels are large in size whereas in B, they are more numerous but smaller in size. These features are observed only on PCBs which have undergone MS agitation. It is uncertain from the image if the features are peaks or depressions, although it is likely that they originate from cavitation features, as discussed in the introduction. If this is the case, then the reduction of pressure of the acoustic wave due to the increase in transducer distance encourages the formation of larger cavitation features (Hauptmann et al., 2013). The qualitative results highlight that closer transducer distances increase the micro-roughness of the PCB surfaces, where smaller cavitation-sized features are favoured. The profile height variations for A and B reveal a maximum Peak-to-Valley variation of $2.83 \mu \mathrm{m}$ and $2.51 \mu \mathrm{m}$, respectively, which are comparatively similar.

When comparing to silent conditions highlighted in Fig 3A, the roughness $R a$ increased by $37 \%$ and $47 \%$ for the transducer positioned at $10 \mathrm{~cm}$ and $1 \mathrm{~cm}$ accordingly. This shows that with MS agitation the 
surface roughness increased significantly at large acoustic powers $(225 \mathrm{~W})$ as observed in section 3.1.2. As the transducer is positioned from 1 to $10 \mathrm{~cm}$ away from the PCB surface, measurements of $R a$ reveal an increase in surface roughness of $7 \%$. This variation is relatively small and could be accounted for by random errors in the data, brought on by the large wavy features across the PCB surface, as explained in section 3.1.2. When sampling the PCB surface it was difficult to choose a sample area to accommodate for the waviness of the PCB as the cavitation features varied in size. A sampling length smaller than $6.1 \mathrm{~mm}^{2}$ would miss the features highlighted in Fig 4A, but not the features in Fig 4B (ASME, 2010).

Using the interferometer, measurements of $R a$ and Peak-to-Valley distances indicated little quantifiable variation between the two surfaces, although plots of the two surfaces displayed qualitative differences in micro-roughening. This highlights that, as the transducer-PCB distance is reduced with corresponding increase of transducer power, the larger resulting pressure increases the frequency of the cavitation but not its magnitude as indicated by $R a$.

Figure 4 White light interferometer plots of Cu plated PCB surfaces of areas $6.1 \mathrm{~mm}^{2}$, with crosssection profiles included underneath. A: transducer positioned $10 \mathrm{~cm}$ from the PCB. B: transducer is positioned at $1 \mathrm{~cm}$.

\subsection{MS plating variation in response to electrical current density}

\subsubsection{Experiment 4: Influence of transducer position on the electrical current distribution}

The fourth experiment explored how changes to transducer position altered the deposited $\mathrm{Cu}$ crystalline properties, through changes of the electrical current distribution. The transducer was positioned 1 $\mathrm{cm}$ away from the PCB surface and toward the centre. The PCB size was $5.20 \mathrm{dm}^{2}$ which was larger than the $1.03 \mathrm{dm}^{2}$ area undergoing agitation. The PCB was plated at $225 \mathrm{~W}$ acoustic power output with an electrical current density of $1 \mathrm{~A} / \mathrm{dm}^{2}$. After the plating cycle, three $\mathrm{Cu}$ finishes were witnessed across the surface and characterised by (1) a sandpaper-like texture appearing as shiny frost-like speckles at the centre of the PCB, (2), a smooth bright finish surrounding the middle frosted region and (3) a nodular, powdery dark finish at the edge of the PCB. SEM images of the individual surfaces are displayed in Table 3 at high and low microscope resolutions. As explained later, the three finishes are characteristic of changes brought on by variations to the electrical current distribution and the behaviour of the chemical additives across the PCB. Such changes have been reported elsewhere (Dini, 1993), predicting how the crystalline behaviour changes in appearance and texture from observations on the macro-scale and micro-sale. For electroplating under current settings lower than $0.5 \mathrm{~A} / \mathrm{dm}^{2}$, the SEM images show that large $\mathrm{Cu}$ face-centre-cubic crystals assemble themselves in a cubic arrangement of larger crystals. The deposit is columnar in nature, which suggests that the deposition occurs along individual grain boundaries (Kocks et al., 2000, Wang and Y. Huang, 2014). Evidence for individual monolayers was highlighted on the cubic structure in the high- 
resolution image. These layers were formed from the $\mathrm{Cu}$ cations being deposited from the solution onto the crystal face, indicating a step layer growth mechanism. Gaps exist between the larger crystal structures which give the deposit a highly brittle structure. During thermal cycling, such copper would undergo fracturing, due to the expansion of the air pockets resulting in the degradation of the PCB. If the electrical current levels are set up correctly and the bath chemistry is properly maintained, then a frosted finish will not be observed after plating. The appearance of the frosted finish here is due to the presence of the metallic transducer, reducing the plating current across the PCB. The electrically conductive surface of the transducer acts as a current thief reducing thereby the effective current density at the PCB surface. This effect has been reported in other sono-electrochemical experiments (Coleman and Roy, 2014). At the regions where current was stolen, the surface of the metal deposited on the PCBs shows a frosted finish indicative of plating at extremely low current densities. Further studies not reported here show that, on increase of the distance between the transducer and the PCB-transducer, the current thieving effect reduces to zero. This was measured by the appearance of the $\mathrm{Cu}$ finish and the plated thickness. It was found that current thieving is negligible when the transducer is placed tangentially at $4.5 \mathrm{~cm}$ from the PCB surface. The frosted finish covered an area smaller than the area of the acoustic agitated area. Around the periphery of the frosting a bright and shiny $\mathrm{Cu}$ finish was deposited. SEM images obtained within this region, as shown in Table 3, highlight a compact fine grain growth of $\mathrm{Cu}$, which is indicative of the standard plating behaviour expected for correct operation of the current settings and appropriate additive concentration levels. A PCB fabricated with this finish will not undergo thermal cycling issues and is desirable as a final product.

Table 3 Plating behaviours observed during megasonic energy assisted electroplating.

At the edge of the PCB a burnt finish was observed. Burning is a standard plating error highlighted by a nodular, dark-brown, powdery deposit formed in regions where the current density exceeds the limited current density, which is typically at the edge of a PCB or on isolated $\mathrm{Cu}$ tracks on the board surface (Schlesinger and Paunovic, 2011). The limited current density influences the operational limit of the current supplied to the PCB. Beyond this value the $\mathrm{Cu}$ cation depletion rate at the surface of the PCB is higher than the repletion rate so as long as the fluid convection is constant. An SEM image of a burnt finish is provided in Table 3 at low ( $20 \mu \mathrm{m}$ on scale) and high ( $500 \mu \mathrm{m}$ on scale) magnifications. The finish is characterised by micro-nodules of $\mathrm{Cu}$ which vary in size from 5 to $250 \mu \mathrm{m}$ in diameter. The variation in nodule size is possibly due to the fast build-up of $\mathrm{Cu}$ on the smaller nodules which act as nucleation sites for the larger ones. A burnt finish is characterised by a weak deposition and is undesirable in PCB fabrication.

When plating under MS assistance, previous work performed indicated that the inclusion of standard bath agitation techniques such as panel movement and/or air bubbles caused disruption and negated some of the benefits of acoustic wave agitation. For this reason, when plating under MS conditions, these two techniques were not included. The inclusion of panel movement and bubble agitation enables replenishment 
of depleted cations near the PCB surface. With the introduction of MS agitation the acoustic streaming currents produced near to the PCB surface provide the same role, enabling higher currents to be applied before burning occurs. Under the plating setup the PCB size was larger than the area agitation by the MS and so, at the edges of the PCB, the MS acoustic streaming failed to spread, reducing the streaming force and the limited current there, thus inducing burning for the current supplied. Further studies have shown that, to prevent burning during MS plating, changes to the transducer position can be made which increase fluid circulation across the PCB. Increasing the tangential distance increases the spread of the acoustic wave across the PCB up to a point, at the expense of reduced acoustic power due to attenuation of the travelling wave. To prevent burning and frosting from occurring entirely on a board, multiple transducers could be deployed, directed at different regions on the PCB, or a transducer the size of the desired area to be plated could be implemented. Under these settings a plating finish would be obtained as highlighted in Table 3 under the standard plating column, where small variations in particle size and fine grain deposition are obtained.

\subsubsection{Experiment 5: Cu crystallinity variation with current density}

A key parameter controlling the growth of $\mathrm{Cu}$ is the electrical current density. If the bath chemistry is maintained within a set range, then the growth of the $\mathrm{Cu}$ is proportional to the current density applied (Sivasankar, 2008). SEM images of the PCB surface plated under different current density regimes are provided in Table 4. Under silent conditions the $\mathrm{Cu}$ was plated at $2 \mathrm{~A} / \mathrm{dm}^{2}$ and $4 \mathrm{~A} / \mathrm{dm}^{2}$. These surfaces displayed no discernible differences and were characterised by a uniform fine grain deposition. When MS plating at $225 \mathrm{~W}$ and with the same current densities, the SEM images revealed different plating finishes to those produced under silent conditions. For MS plating at $2 \mathrm{~A} / \mathrm{dm}^{2}$, a uniform surface deposition was observed, although a large polycrystalline deposit was also apparent. For MS plating at $4 \mathrm{~A} / \mathrm{dm}^{2}$, a spiky whisker-like growth was observed, as discussed in section 3.1.1. The cause behind the polycrystalline and the whisker formations suggested that the bath additives were performing incorrectly. The plating bath additives $\mathrm{Cu} 111$ and $\mathrm{Cu} 114$ enable grain refinement of the $\mathrm{Cu}$ deposit and a failure of their behaviour can lead to large grain deposits.

Table 4 SEM images of PCB surfaces plated under varying current densities and MS-agitation.

The poor performance of the bath additives could be explained by their low concentrations near the PCB surface due either to the force of acoustic streaming waves on the PCB surface, which can remove organic molecules, similar in structure to the bath additives, off a surface (Hennig et al., 2009), or by denaturing the additives under large thermal increases, brought on by megasound cavitation (Hauptmann et al., 2013). In additional plating trials, reductions in acoustic pressure have shown to improve the condition of 


\section{Circuit World}

the surface finish up to a point, after which, the reduction in electrolyte transport produces an undesirable burnt finish, as explained in section 3.2.1.

\section{Copper artefacts due to MS plating}

Acoustic assisted plating has been shown to strongly influence the characteristics of electrodeposited $\mathrm{Cu}$. A variety of other plating effects have also been observed in experiments 1-5, which are attributed to acoustic artefacts from the MS interaction with the electrodeposit. The artefacts include cavitation and periodic copper features. These plating effects are discussed along with their potential impact on PCB fabrication.

\subsection{Megasonic induced cavitation features}

Cavitation is a unique artefact observed under acoustic agitation. It varies in intensity and magnitude depending on the acoustic pressure and frequency. Cavitation has been widely reported under US agitation (Gale and Busnaina, 1999). Cavitation can be observed on a surface because of the damage caused when highly pressurised thermal energy is released from bubble collapse. The damage is typically observed as crater-like features, although it may also be manifested as a micro-roughening of the surface. The energy released is observed as a jetting micro-stream. The jet stream is typically directed tangentially towards the surface the bubble is against, although it is possible for the jet stream to become directed along the surface, if the bubble undergoes influence from external, directional convection currents (Zhou and Gao, 2013).

Fig 5A presents an example of cavitation observed during one of the investigations on a PCB surface plated under MS. The circle, of diameter of around $400 \mu \mathrm{m}$, is possibly a crater nucleus from where the bubble imploded and the tail of length of about $2 \mathrm{~mm}$ is the jet stream, as the bubble was directed along the surface by acoustic streaming currents. These features are characteristic of acoustic cavitation and are not observed under standard plating. A high resolution SEM image of a MS plated PCB surface is given in fig 5B. Features are present which appear similar to the cavitation measured on the larger scale. The features, many of them occurring on the surface with the same orientation, appear to display the same nucleus and tail features, albeit at a smaller scale. Previous studies into cavitation influences have indicated that some cavitation, occurring at high frequencies $(1 \mathrm{MHz})$, would be on a scale too small to be detected by standard employed techniques such as sono-luminescence (Gale and Busnaina, 1999, Lucke and Beecham, 2009). The cavitation features are, to the best of the authors' knowledge, the first examples ever recorded for plated copper surfaces.

Circle features and pits were readily observable on the PCB's surface after MS plating. They varied in size and could be observed by eye on the macroscale down to the microscale. The increase of roughness mentioned in sections 3.1.2 and 3.1.3, could have been brought on by micro-cavitation features. 
Figure 5 Observations of megasonic assisted cavitation. A) Obtained using an interferometer, scale in image $1 \mathrm{~mm} \mathrm{~B}$ ) SEM image, scale in image $5 \mu \mathrm{m}$.

\subsection{Measurements of copper ridges and surface acoustic waves}

When an MS wave is directed onto a PCB surface, a part of the wave may be scattered and then confined to a thin layer near the board surface. The conditions for this confinement depend on the free acoustic wavelength, the acoustic impedance at the board surface and the angle scattered. The confined evanescent waves are called Rayleigh-wave Surface Acoustic Waves (SAWs), which exponentially decay perpendicularly to the board surface (Rienstra and Hirschberg, 2013). SAWs travel in the plane of the board and are an example of boundary layer acoustic streaming. If a SAW is generated on a rigid surface which has had organic molecules attached, it is seen that the molecules are being displaced. If the additives in a plating bath behave in the same manner, they may become displaced into nodal regions which exist between the oscillating high and low pressure maximums within the SAW (Hennig et al., 2009). Additive movements may occur in a periodic fashion where regions of high and low density are formed, separated by half of the acoustic wavelength, $\lambda$.

Under MS plating $\mathrm{Cu}$ features separated by $\lambda / 2$ have been observed, as shown in Fig 6. Fig $6 \mathrm{~A}$ shows a top-down image of concentric ringlets emanating from a tooling hole on a PCB. The ringlets appeared as periodic deposits of large-grain $\mathrm{Cu}$ growths which were observed as a dull finish on the PCB. The distance between the ringlets was around $0.7 \mathrm{~mm}$, which corresponds to $\lambda / 2$ of the $1 \mathrm{MHz}$ wave in the electrolyte solution. The appearance of the periodic ringlets suggest the generation of a SAW on the PCB surface. The ringlets are characterised by a deposition of large grains and a possible mechanism for their formation is that they are due to low concentrations of additives at the SAW pressure maxima. In turn, in the pressure nodal regions, the additives would congregate, increasing in concentration and encouraging a shiny, fine grain deposit in between the matt-finished ringlets.

The SAW influence on plating is not limited to changes in plating finish. Variations to $\mathrm{Cu}$ thickness were also observed on the PCB surface, as shown in Fig 6B where periodic ridges are observed on an MS plated PCB surface. The ridges are separated again by around $0.7 \mathrm{~mm}$ and are characterised by peaks and valleys. Ridges occurred on both sides of the board, although, during some trials, they would appear greater on one side of a panel rather than the other. This was possibly due to the interplay between the absorption and transmission of the wave through the PCB. The ridge orientation was typically vertical to the board orientation in the bath and changes to the angle of incidence of the acoustic waves altered their positions and orientation across the surface. Motions in either the panel or the transducer appeared to alter the position of the ridges. If cathode rail movement was included, the occurrence of the ridges on the board would be reduced, although it would not entirely subside. The MS plated $\mathrm{Cu}$ finish on the ridges appeared shiny, which suggests the correct behaviour of the brightener additives and the formation of a fine-grain deposit. The possible reason as to why a dull finish was not observed could be related to the formation of stable 
cavitation. Unstable cavitation would lead to a dull matt finish due to improper additive behaviour, as explained in section 3.2.2. Despite the desired shiny uniformity of the $\mathrm{Cu}$ finish, the ridges induced a variation of $20 \mu \mathrm{m}$ in plating uniformity as measured from cross-sections. This variation is larger than the minimum acceptable by IPC specifications and so the ridges in their current form are an undesirable artefact.

Figure 6 Images of surface acoustic waves in electrodeposited copper. A) Formation of ringlets with scale bar $0.5 \mathrm{~mm}$. B) Ridges with scale bar $1 \mathrm{~mm}$.

\section{Conclusions}

\subsection{Whisker growth due to high electrical currents and MS power}

MS plating trials investigated the influence of the acoustic power emitted by the transducer on the characteristics of the electrodeposits. On maximum acoustic output power, $450 \mathrm{~W}$, observations on the macroscale revealed a shiny electrodeposit on the surface, which was expected for standard fabrication and suggested a fine-grain ductile microscale finish. On observations of its microstructure the $\mathrm{Cu}$ structure appeared spiky, with large whisker-like formations. Whisker growths were also observed during MS plating with high electrical currents of $4 \mathrm{~A} / \mathrm{dm}^{2}$. Whisker growth is undesirable and was the product of the high electrical currents and the large acoustic powers. The acoustic power induces an acoustic streaming force on the PCB surface as well as exothermic MS cavitation. The two effects combined could have a negative impact on the organic chemical additives on the PCB surface, which under typical plating operation, ensure grain refinement.

Thermal increases brought on by MS cavitation effects could induce denaturing of the additives and the acoustic streaming force could displace and remove the attached organic molecules. A whisker-like deposition is undesirable in PCB fabrication due to its susceptibility to fracturing and breaking under thermal expansion, leading to reduced PCB life time and electrical shorts. To reduce the impact of this plating finish, modifications to the MS plating cycle could be implemented, such as the introduction of an off-cycle during the plating cycle, or plating on lower current densities and acoustic powers.

\subsection{Micro-roughening due to transducer position alteration and power change}

The introduction of MS agitation increased micro-roughening on the plated PCB surface. The microroughening appeared to increase with increases in transducer power output and on the reduction in distance of the transducer device. For smaller tangential transducer/PCB distances, attenuation of the acoustic wave was less, enabling higher acoustic powers over the PCB surface per unit area. An increase in acoustic power is realised by increases in pressure. Increases to acoustic pressure are reported to increase the intensity of cavitation collapse (Ebnesajjad, 2010) and so, the micro-roughening behaviours witnessed could be accounted for by an increase of cavitation power on transducer distance reduction and power output increase. 
Controlling roughness on a plated $\mathrm{Cu}$ surface is important as roughness impacts on PCB manufacture, where increases in manufacturing performance are obtained for increases to roughness up to a point where further increases led to electrical signal loss at high operating electrical frequencies.

The current trend in PCB design is towards high interconnect density, high-frequency applications (Beers and Minten, 2011). The introduction of MS plating aims to reduce interconnect features on a PCB, reducing track pitch and providing low surface roughness of metal tracks for high frequency applications. The surface roughness values measured as a result of the MS are larger than desired for high-frequency PCB fabrication. Fabricating under these conditions is currently counterproductive for the development of future product technological trends. A reduction in roughness during MS plating could be made by making modifications to the plating cycle. Reducing the acoustic pressure output towards the end of a plating cycle would ensure that the plating finish at the end of the cycle would undergo less cavitation and a more uniform finish. Additionally, introducing an off-cycle during plating would on average reduce the cavitation influence. Further studies are required into the influence of more complex MS plating cycles where on/off duty cycle and acoustic pressure are altered.

\subsection{Current distribution due to current thieving.}

Observations were made as to how the electrical current distributed across the PCB due to a current thieving effect, along with the acoustic streaming force reduction, influences the crystallinity of the electrodeposited metal. A spectrum of plating behaviours was observed which are characteristic of high and low plating currents. The behaviours were induced primarily due to a transducer-distance related effect, brought on by the thieving of electrical current away from the PCB. The current variation induced by the close proximity of the device to the cathode surface, produced the low quality plating finish. To enable a high quality finish whilst applying the MS, it was found that increasing the transducer tangential distance reduced the current thieving effect. At around $4.5 \mathrm{~cm}$ from the PCB the finish variation was negligible and a bright and shiny finish was produced. The results show that, to form a high-quality bright plating finish when MS plating, a minimum tangential distance must be found for the transducer device being used. This value may alter depending on the size and shape of the transducer. Further electrochemical investigations are required to assess more thoroughly the influence of transducer surface conductivity on current thieving, as changes may be made to the transducer surface to reduce electrical conductivity, such as the deposition of a non-electrically conductive layer.

When the acoustic streaming force failed to cover the entire face of the $\mathrm{PCB}$, the $\mathrm{Cu}$ cation replenishment rate suffers in electrically isolated regions, inducing unwanted burning of the $\mathrm{Cu}$ deposit. This result shows that, for the effective fabrication of a PCB when MS plating, the acoustic agitation must cover the total plated area, especially if the panel movement and bubble agitations are switched off. 


\subsection{MS Acoustic plating artefacts}

Unique MS acoustic agitation artefacts were observed on the electrodeposited $\mathrm{Cu}$. These were possibly generated by the formation of SAWs on the PCB surface in response to back reflections of the acoustic wave. In PCB manufacture the presence of a SAW is detrimental to $\mathrm{Cu}$ uniformity. To enable a uniform deposition of $\mathrm{Cu}$, the formation of a SAW should be prevented by reducing the occurrence for resonant acoustic frequencies to form on the PCB. One method is to vary the frequency output from the transducer, by either sweeping across a finite range (Erpelding et al., 2007) or randomly switching between values (Tang and Clement, 2009b). Frequency variation suffers from issues of low power coupling into individual acoustic modes, which may or may not be critical in MS plating. An alternative method is to alter the phase of the acoustic wave over discreet time intervals, known as phase-shift-keying (PSK)(Tang and Clement, 2009a). PSK has been demonstrated at ultrasound frequencies and produces improved standing wave reduction performance, but without any drastic change to the frequency output. When installing a transducer for use in MS plating, frequency shifting and or phase shifting should be considered, although the addition of these features increases the costs of the device.

\subsection{Sub-micron bubble influence on plating}

MS has been introduced into PCB plating to investigate improved $\mathrm{Cu}$ deposition in terms of uniformity within fine feature THV interconnects. Increasing fluid transport is a critical factor for the increase of plating uniformity down THVs due to the enhancement of electrolyte transport. It is difficult to induce fluid convection down THVs of high aspect ratio $(10: 1)$ and small diameter size $(<0.3 \mathrm{~mm})$ due to the increased influence of viscous forces over inertial forces. Previous simulations have highlighted that the increases to forced streaming currents by MS acoustics are weak, so as to not significantly contribute to fluid transport down high aspect ratio vias (Strusevich et al., 2013). Regardless, increases to plating efficiencies have been observed (Costello et al., 2013).

Evidence for sub-micron bubbles was witnessed on the MS plated PCB surfaces from images of micro-cavitation. Under megasonic agitation, acoustic streaming is produced, causing microbubbles in solution to be transported within the streaming current. A secondary influence on fluid transport is the potential increased movement of solution due to the passage of these microbubbles (Cravotto et al., 2013). This effect has been reported under ultrasound agitation and evidence of enhanced fluid convection around the microbubbles has been provided in terms of Particle Image Velocimetry measurements and simulations using the COMSOL ${ }^{\mathrm{TM}}$ software package (Collis et al., 2009). The presence of sub-micron bubbles observed on the PCB surface during the investigations, suggests that they could influence the plating deposition properties, as do microbubbles in US plating and could be an influential factor in improving fluid transport in and around the THVs, enabling the plating enhancements witnessed. Few simulations have been made into the potential for increased electrolyte transport due to sub-micron bubble transport. New and improved models behind the plating interactions are required to develop the mechanism for MS fluid transport, which 
in turn can be used to successfully manipulate and control the positive plating benefits, and overcome the issues brought on due to unstable cavitation.

\subsection{Overall conclusion}

MS introduction into electrochemistry is a relatively new field of study and its potential positive impact on fabrication is contended by adverse plating effects. Despite the initial shortcomings of the technology, remedies exist, although each requires a re-evaluation of the plating bath parameters. To bring about the ever-demanding increases to PCB technological development, alterations to the electrochemical setups may be required which mirror this changing landscape. Megasound technology could play a key role in this future, however further electrochemical and sonochemical investigations are needed before implementation can take place in a PCB fabrication line.

\section{Bibliography}

Abdollah, S., Banks, C. E. \& Compton, R.G. (2003). "Ultrasonic effects on the electro-reduction of oxygen at a glassy carbon anthraquinone-modified electrode. The Koutecky-Levich equation applied to insonated electro-catalytic reactions". Physical Chemistry Chemical Physics, 5, pp. 3988 - 3993.

Asme (2010). Surface Texture: Surface Roughness, Waviness and Lay, American Society of Mechanical Engineers.

Beers, J. \& Minten, K. (2011). "PCB technology Future Trend". IEEE 802 LAN/MAN Standards Committee. Available at: http://www.ieee802.org/3/bj/public/nov11/minten_01a_1111.pdf (Accessed 1 March 2016).

Brennan, R.E. (2007). Ultrasonic Nondestructive Evaluation of Armor Ceramics, Rutgers The State University of New Jersey - New Brunswick.

Brotchie, A., Grieser, F. \& Ashokkumar, M. (2009). "Effect of Power and Frequency on Bubble-Size Distributions in Acoustic Cavitation". Journal of Physical Review Letters, 102, pp. 1- 4.

Coleman, S. \& Roy, S. (2014). "Effect of Ultrasound on mass transfer during electrodeposition for electrodes separated by a narrow gap". Elsevier, Journal of Chemical Engineering Science, 11, pp. 35-45.

Collis, J., Manasseh, R. , Liovic, P., Tho, P. , Ooi, A. \& Duran, K. P. (2009). "Cavitation microstreaming and stress fields created by microbubbles". Elsevier Publishers, Journal of Ultrasonics, 50, pp. 273 279.

Costello, S., Strusevich, N., Flynn, D., Kay, R.W., Patel, M.K., Bailey, C., Price, D., Bennet, M., Jones, A.C. \& Desmulliez, M.P.Y. (2013). "Electrodeposition of copper into high aspect ratio PCB micro-via using megasonic agitation". Springer Verlag, Journal of Microsystems Technology, pp. 1-8.

Cravotto, G., Gaudino, E.C. \& Cintas, P. (2013). "On the mechanochemical activation by ultrasound". Journal of Chemical Society Review, 42, pp. 7521 - 7535.

Dini, J. W. (1993). Electrodeposition: The Materials Science of Coatings and Substrates, Noyes Publications, Germany, Berlin.

Ebnesajjad, S. (2010). Handbook of Adhesives and Surface Preparation: Technology, Applications and Manufacturing, Elsevier Science.

Erpelding, T.N., Hollman, K.W. \& O'donnell, M. (2007). "Bubble-based acoustic radiation force using chirp insonation to reduce standing wave effects". Journal of Ultrasound in Medicine and Biology, 33, pp. $263-269$.

Etter, P.C. (1995). Underwater Acoustic Modeling: Principles, techniques and applications, Second Edition, Taylor \& Francis.

Gale, G. W. \& Busnaina, A. A. (1999). "Roles of Cavitation and Acoustic Streaming in Megasonic Cleaning". Particulate Science and Technology: An International Journal, 17, pp. 229-238. 
Garich, H., Gebhart, L., Taylor, E.J., Inman, M. \& Mccrabb, H. (2007). "Development and Characterization of Plating Cell Geometry for Printed Circuit Board and Packaging Applications". Journal of The Electrochemical Society, 3, pp. 1- 10.

Gurrum, S.P., Edwards, D.R., Marchand-Golder, T., Akiyama, J., Yokoya, S., Drouard, J \& Dahan, F 2012. Generic Thermal Analysis for Phone and Tablet Systems. Electronic Components and Technology Conference (ECTC), 2012 IEEE 62nd. IEEE.

Hauptmann, M., Struyf, H., Gendt, S. D., Glorieux, C. \& Brems, S. (2013). "Evaluation and interpretation of bubble size distributions in pulsed megasonic fields". Journal of Applied Physics, 113, pp. 1-17.

Hennig, M., Neumann, J., Wixforth, A., Radler, J. O. \& Schneider, M. F. (2009). "Dynamic patterns in a supported lipid bilayer driven by standing surface acoustic waves". The Royal Society of Chemistry, Lab on a Chip, 9, pp. 3050-3053.

Hoffelner, J., Landes, H. \& Lerch, R. (2000). "Calculation of Acoustic Streaming Velocity and Radiation Force Based on Finite Element Simulations of Nonlinear Wave Propagation". IEEE Ulrasonics Symposium, 2000. IEEE, pp. 585 - 589.

Hyde, M.E. \& Compton, R.G. (2002). "How Ultrasound influences the electrodeposition of metals". Elsevier Publishers, Journal of Electroanalytical Chemistry, 531, pp. 19 - 24.

Ipc 1999. IPC-A-600F. Acceptability of Printed Boards, IPC Association Connecting Electronics Industries. Northbrook, IL 60062-6135:

Kaufmann, J. , Desmulliez, M.P.Y, Price, D., Hughes, M., Strusevich, N. \& Bailey, C. "Influence of megasonic agitation on the electrodeposition of high aspect ratio blind vias". 2nd Electronics System integration Technology Conference, 2011 Greenwich, UK. IEEE, pp. 1235-1241.

Kaufmann, J.G., Desmulliez, M.P.Y., Tian, Y., Price, D., Hughes, M., Strusevich, N., Bailey, C., Liu, C. \& Hutt, D. (2009). "Megasonic agitation for enhanced electrodeposition of copper". Springer, Microsystems and Technology, 15, pp. 1245-1255.

Kocks, U.F., Tomé, C.N. \& Wenk, H.R. (2000). Texture and Anisotropy: Preferred Orientations in Polycrystals and Their Effect on Materials Properties, Cambridge University Press.

Lee, D. M., Folkerts, J. T., Collins, F. L., Dietrich, A. E. \& Keeney, A. (2010). "Comparison of the Electrochemical and Physical Properties of Nanocrystalline Copper Deposition in the Fabrication of Printed Wiring Boards ". IPC APEX EXPO Technical Conference 2010 Las Vegas. IPC, pp. 492 451.

Lucke, T. \& Beecham, S. (2009). "Cavitation, aeriation and negative pressures in siphonic roof drainage systems". Building Serv. Eng. Res. Technol, 30, pp. 103-121.

Martin, S. (2013). Sonocrystallization of Fats, Springer.

Minzari, D., Grumsen, F.B., Jellesen, M.S., Moller, P. \& Ambat, R. (2011). "Electrochemical migration of tin in electronics and microstructure of the dendrites". Elsevier, Journal of Corrosion Science, 53, pp. 1659-1669.

Muller, S., Reuschel, T., Donadio, R.R., Kwark, Y.H., Bruns, H.D. \& Schuster, C. (2015). "Energy-Aware Signal Integrity Analysis for High-Speed PCB Links". IEEE Transactions of Electromagnetic Compatability, 57, pp. 1226 - 1234.

Okubo, T. , Shibaura, T.S., Hosoi, T., Tsuyoshi, H. \& Mitsui, F.K. (2013). "Signal Transmission Loss on Printed Circuit Borad in GHz Frequency Region". IEEE Electrical Design of Advanced Packaging \& Systems Symosium (EDAPS), 2013 Nara, Japan. IEEE, pp. 112 - 115.

Peiponen, K.E., Myllylä, R. \& Priezzhev, A.V. (2009). Optical Measurement Techniques: Innovations for Industry and the Life Sciences, Springer.

Rienstra, S.W. \& Hirschberg, A. (2013). IWDE 92-06: An Introduction to Acoustics, Publisher: Eindhoven University of Technology.

Roelfs, B., Dambrowsky, N., Erben, C \& Kenny, S. (2013). "Filling Through Holes and Blind Micro Vias With Copper Using Reverse Pulse Plating And Insoluble Anodes". Atotech. Available at: http://www.atotech.com/fileadmin/pdf/papers/el/Roelfs_Kenny_Through_hole_BMV_filling.pdf (Accessed Accessed 18th April).

Schlesinger, M. \& Paunovic, M. (2011). Modern Electroplating, Publisher: John Wiley \& Sons,New Jersey, USA.

Sivasankar, B. (2008). Engineering Chemistry, McGraw-Hill Education,New Delhi. 
Strusevich, N., Desmulliez, M.P.Y., Abraham, E., Flynn, D., Jones, T., Patel, M. \& Bailey, C. (2013). "Electroplating for high aspect ratio vias in PCB manufacturing : enhancement capabilities of acoustic streaming". Springer Verlag, Journal of Advanced Manufacturing, pp. 211-217.

Tang, S.C. \& Clement, G.T (2009a). "Acoustic standing wave suppression using randomized phase-shiftkeying excitations (L)". Journal of Acoustical Society of America, 126, pp. 1667 - 1671.

Tang, S.C. \& Clement, G.T. (2009). "Standing wave suppression in transcranial ultrasound therapy using random-signal-modulation excitation". International Ultrasonics Symposium, 2009b. IEEE, pp. 2048 $-2051$.

Trelleborg. (2008). "Aerospace Engineering Guide". Trelleborg Sealing Solutions. Available at: www.tss.trelleborg.com (Accessed 3 March 2016).

Verdan, S., Burato, G., Comet, M., Reinert, L. \& Fuzellier, H. (2003). "Structural changes of metallic surface induced by ultrasound". Elsevier, Journal of Ultrasonics Sonochemistry, 10, pp. 291-295.

Verhaagen, B. \& Fernández, R. D. (2016). "Measuring cavitation and its cleaning effect". Ultrasonics Sonochemistry, 29, pp. 619-628.

Wang, J. \& Y. Huang, T. Yu, S. Zhu, M. Shen, W. Li, J. Wang (2014). "The migration of Cu species over Cu-SAPO-34 and its effect on NH3 oxidation at high temperature". Journal of the Royal Society of Chemistry, Catal. Sci. Technol, 4, pp. 3004-3012.

Yan, J.J., Chang, L.C., Lu, C.W. \& Dow, W.P. (2013). "Effects of organic acids on through-hole filling by copper electroplating". Electrochimica Acta, pp. 1 - 12.

Zhou, Y. \& Gao, X. W. (2013). "Variations of bubble cavitation and temperature elevation during lesion formation by high-intensity focused ultrasound". Journal of Acoustical Society of America, 132, pp. 1683-1694.

Zygo. (2016), "NewViewTM 8000 Series". available at: http://www.zygo.com/?/met/profilers/newview8000/ (Accessed 1 March 2016). 